\title{
el maestro ignorante: disonancia y emancipación
}

alejandro del valle ${ }^{1}$ universidad nacional de san martín - argentina

"Maestro ignorante", "explicador embrutecedor", "inferiores superiores", “desrazonar razonablemente"... Una disonancia se expresa en los casos de oxímoron. El maestro ignorante es la historia de esta disonancia, de su rastreo histórico, de sus metamorfosis a lo largo del tiempo, de su impasible actualidad. En este estudio, reeditado por Libros del Zorzal, Jacques Rancière retoma la experiencia pedagógica de un educador francés del siglo XVIII, Joseph Jacotot, quien luego de servir como artillero en los ejércitos de la República durante la Revolución Francesa y ser forzado a exiliarse en los Países Bajos a causa de la restauración monárquica, logró enseñar francés a sus alumnos valiéndose únicamente de una versión bilingüe del Telémaco de Fénelon. Jacotot no sabía flamenco y sus alumnos no conocían una palabra de francés. El acto educativo, sin lenguaje en común entre profesor y alumnos, se concretó exitosamente. ¿Sin lenguaje en común? Como sucede muchas veces, la excepción a la regla dice más que la regla misma. Esto pasa con la experiencia de Jacotot, pues vale más por su peculiaridad que por la norma que pretende darle sentido.

La primera edición francesa de El maestro ignorante salió a la luz en 1987, en medio de la disputa pedagógica surgida a partir de la llegada al poder del Partido Socialista en Francia. Por un lado, los "bourdieristas", quienes a partir de los conceptos de la sociología progresista ponían el acento en la violencia simbólica, proponían un programa que apuntaba a reducir las desigualdades de la escuela adaptando y haciendo más accesible el saber para las "poblaciones desfavorecidas". Por otro lado, la ideología llamada "republicana" sostenía que la potencia de la igualdad consistía en la universalidad de un saber distribuido a todos por igual, sin tener en cuenta el origen social. Rancière interviene en el debate rompiendo por el

\footnotetext{
${ }^{1}$ E-mail: alejandrodelvalle1986@yahoo.com.ar 
vértice: ni la transmisión neutra del saber, ni la adaptabilidad del saber al estado de la sociedad escapan al paradigma pedagógico que encuentra su razón de ser en la reconstitución y proliferación indefinida de la desigualdad que promete suprimir. Esta es la disonancia que Rancière rescata, que trae al presente "rehaciendo las frases" de Jacotot para resignificar y recontextualizar una voz solitaria y disonante, que se alzó como estandarte del impulso igualitario de la Revolución Francesa en los albores mismos de la fundación de valores que hoy rigen nuestra sociedad, proclamando que los mismos métodos por los cuales la sociedad se propone poner fin a la desigualdad son los métodos que la garantizan.

La peculiaridad del "caso Jacotot" permite encuadrar el análisis en los marcos de la pedagogía. El caso es instructivo porque echa luz sobre la extrañeza misma de la relación pedagógica y porque en su profundidad yace el crujido de una disonancia y de un nuevo oxímoron: "orden y progreso". Orden: poner fin a la vehemencia revolucionaria y a la era de la fiebre igualitaria. Progreso: consolidar en una nueva disposición social e institucional las necesarias transformaciones de las cuales la revolución había sido la realización anticipadora y fantasmática. A lo largo del libro de Rancière se pueden rastrear las raíces históricas de una fórmula que en estas latitudes resuena menos como la expresión de las bondades del progresismo que como el dictamen de una sentencia: “jorden y progreso!” bramaban los caudillos locales mientras decretaban la "paz" con la espada y mestizaban el "progreso" en la más módica y pastoril "administración". En aquel intento de síntesis histórica que pretende expresar y contener dicha fórmula, se define el equilibrio inestable de una época y su condensación en la institución educativa, equilibrio inestable de fuerzas políticas, de relaciones sociales, de instituciones y, claro está, de toda la sociedad de clases. Naturalmente, la conciliación de orden y progreso encontrará su modelo en una institución en la cual "el ejercicio de la autoridad y la sumisión de los sujetos no tiene otro objetivo que la progresión de esos sujetos hasta alcanzar el límite de su capacidad" (p. 10). Esa institución es la escuela. 
La "emancipación intelectual" consiste en sustraerse al mensaje de inferioridad e incapacidad que repite sin cesar la enseñanza institucionalizada. El emancipado puede enseñar lo que ignora porque está seguro de su propia capacidad de aprendizaje y porque en su propio aprender se verifica la igualdad de todas las inteligencias. A lo largo de los cinco capítulos que constituyen el libro, el/la lector/a descubre las nociones principales, como así también los pormenores de las "disonancias fundamentales" que devela la experiencia de Jacotot. Un breve repaso por ellos:

En el primer capítulo, "Una aventura intelectual”, Rancière reconstruye la experiencia de Jacotot y expone las paradojas de la relación pedagógica. La sumisión de una inteligencia a otra encuentra su concreción en la relación entre profesor (propietario del saber) y alumno (sobre quien se deposita el saber), basada en la mayéutica socrática. La figura de Sócrates, retomada por Rancière, no es la del maestro emancipador, sino la del embrutecedor por excelencia, pues enfrenta al alumno a las aporías y lagunas de su propio discurso del que sólo puede salir comandado por las preguntas del maestro que lo guía progresivamente hacia el saber. El modelo de enseñanza basado en la mayéutica socrática, dirá Rancière lapidariamente, es un método perfeccionado de embrutecimiento, es la lección de la propia incapacidad. El maestro no transmite su ciencia y se puede enseñar aquello que se ignora. Explicar es embrutecer.

El segundo capítulo, "La lección del ignorante", se centra en aquello que los contemporáneos de Jacotot llamaban "el método". Sin embargo, a lo largo del capítulo queda claro que el abordaje de la problemática pedagógica no es una discusión de métodos, sino de contenido y de principios: "Todas las inteligencias son iguales" y "No hay nadie que no sepa alguna cosa". Quien parta de estos principios verificará su veracidad en los resultados, quién parta de una concepción jerarquizada de las inteligencias transmitirá el embrutecimiento que le fue inculcado, pues no se puede emancipar sin estar emancipado. 
Un punto muy interesante abordado en este capítulo es la idea de que el trabajo intelectual y el trabajo manual son manifestaciones del mismo trabajo y de la misma inteligencia. Las distintas esferas del saber humano se entienden como distintos "lenguajes" a aprender y todos ellos se aprenden de la misma manera en que se aprende la lengua materna: por necesidad, por deseo y por la propia experiencia. ¿Qué había en común entre Jacotot y sus alumnos, cuando aquél logró enseñarles francés? La misma inteligencia rastreable en la materialidad del Telémaco.

A lo largo del capítulo tercero, "La razón de los iguales", Rancière indaga en los principios de la afirmación esencial de Jacotot, mientras transita por los debates filosóficos y políticos que se daban al respecto en el marco de la restauración bonapartista de la revolución. Se discute a partir del núcleo fundante de la filosofía moderna, el cogito cartesiano, y se busca, a lo largo de todo el capítulo, una perspectiva para filosofar y encontrar los principios de los modelos pedagógicos. Se indaga en los problemas del lenguaje y en la lección de los poetas como expresión de la experiencia humana, de los sentimientos y de las "aventuras intelectuales" de las que cualquier mente es capaz. El poeta, el artista, el filósofo buscan en la comunicación el reconocimiento de su desciframiento, buscan conectarse con sus iguales, ser entendidos y comunicarse, presuponiendo la igualdad con quienes los descifran. El lenguaje es la materialidad, es la cosa común entre dos inteligencias que se saben iguales y que se reconocen en la objetividad de la materia: el lenguaje, el arte, el libro o cualquier expresión de la inteligencia. "El hombre dotado de razón puede hacer todo, pero debe aprender la lengua propia de cada una de las cosas que él quiere hacer" (p. 115, 2016).

El orden de la pedagogía establecida, el orden de las desigualdades, se descarga contra Jacotot y la locura de su enseñanza. Durante el cuarto capítulo, "La sociedad del desprecio", Rancière retoma y resignifica las reflexiones de Jacotot acerca del orden social, acerca de la masa inerte del orden social que, sostenido por el orden de la desigualdad, descarga su desprecio sobre las voluntades. En este terreno 
predomina la retórica y nadie se comunica para ser escuchado, se habla para provocar el silencio, para dominar una voluntad e inducir una acción. La retórica no es el medio para compartir la experiencia humana, es el medio por el cual se reproduce la desigualdad entre los superiores y los inferiores, es el medio por el cual la palabra no busca ya su desciframiento, sino la sumisión de un silencio. La retórica es lo contrario a la poesía y es la forma que toma el lenguaje en el ámbito de la sinrazón, en el ámbito de las disputas políticas. Sin embargo los emancipados sabrán desrazonar, sabrán ver el arte de la inteligencia humana en la retórica y sabrán sobre todo hablar para defender sus posiciones. No existe la sociedad razonable, pero existe el milagro de que por momentos la sociedad se mire a sí misma razonablemente.

El quinto y último capítulo, "El emancipador y su mono", expone la experiencia de Jacotot como director de una escuela militar normal en Lovaina. La mala experiencia que resulta de la aplicación institucionalizada de los principios pedagógicos de Jacotot se resuelve en la imposibilidad de institucionalizar una voluntad y una capacidad que acontecen en el individuo. El "método Jacotot", orientado principalmente hacia los pobres y padres de familia con el fin de que emancipen a sus hijos, no encuentra lugar de concreción en la progresiva y total institucionalización social de la enseñanza o, dicho de otra forma, en la “infantilización" o embrutecimiento general de los individuos.

Hay muchas formas de leer esta obra de Rancière. Una de ellas es como reveladora de mitos. En este caso se trata del mito primogénito que emerge durante esa "era de transición", al amalgamar el "progresismo" de los saberes al "progresismo" igualitarista del devenir social. Es aquello que Rancière llama la "sociedad pedagogizada" en la que "[...] el Progreso es la ficción pedagógica erigida en ficción de la sociedad toda" (p. 190, 2016). En otras palabras, se trata de la idea de que la "reducción" de las desigualdades sociales se logra con la educación y la instrucción del pueblo. Rancière dispara contra esta idea, al mismo tiempo que dispara contra el sentido común de toda una época, un sentido tan difícil de 
comprender por la ocultación de su simpleza, por su inconsciente naturalización y aceptación en un sinnúmero de expresiones que le dan sustento. La contracara de esta idea, claro está, es la justificación de las desigualdades en la jerarquización de los saberes. De esta manera el mito de la solución progresista a las desigualdades sociales pasa a ser la justificación erudita y elitista de un orden social que tiene en esas desigualdades su razón de ser. El modelo pedagógico toma la forma precisa para justificar y reproducir la sociedad a la que sirve.

En esta nueva edición ampliada, que incluye una entrevista al propio Rancière, el autor de La noche de los proletarios cuenta que se "encontró" con Jacotot mientras hurgaba en los archivos de la historia de la clase obrera francesa. El interés por las investigaciones referidas a la vida obrera determina el quehacer intelectual de Rancière después de su experiencia en los sucesos de Mayo del '68. A partir de ese momento, Rancière rompe con la línea estalinizada del PCF (Partido Comunista Francés) y plantea un perspectiva de fuerte contraste con Althusser, con quién había colaborado algunos años antes en la obra colectiva Para leer el capital (1965), llegando a la conclusión de que el "althusserianismo" es un "pensamiento del orden" que remite al conservadurismo de su presupuesto: "el 68 no existió". Luego realiza una experiencia política en el maoísmo de izquierda y también colabora en el Grupo de Información sobre las Prisiones (GIP), impulsado por Michel Foucault, de quien se distancia ideológicamente a mediados de la década del '70. De la lectura de El maestro ignorante surge la pregunta acerca de las relaciones entre los postulados de la emancipación intelectual y el tipo de práctica de emancipación social que aquellos deberían fundamentar. Sin embargo, el libro no plantea ni discute ningún postulado para una práctica colectiva emancipatoria.

El maestro ignorante es una obra de innegable actualidad que constituye un importante punto de apoyo para una reflexión crítica sobre las prácticas pedagógicas concretas que se realizan día a día en miles y miles de establecimientos educativos, como así también sobre aquellas leyes y políticas que rigen e institucionalizan estas 
prácticas. Se trata de una obra que nos invita a cuestionarnos sobre el fundamental e inmenso valor de los saberes para la vida y sus "disonancias" con los modelos y sistemas educativos.

\section{referencias}

RANCIÈRE, Jacques. El maestro ignorante: Cinco lecciones sobre la emancipación intelectual. Buenos Aires: Libros del Zorzal, 2016. 253p.

recibido en: 30.12 .2016

aprobado en: 28.01.2017 